\title{
Şantiyelerde Risk Değerlendirmesinin PHL Tekniği İle İrdelenmesi
}

\author{
Selim Taşkaya ${ }^{\mathrm{a}{ }^{*},}$,Muhammed Fatih $\mathrm{Can}^{\mathrm{b} 2}$ \\ ${ }^{a}$ Artvin Meslek Yüksekokulu, Mimarlık ve Şehir Planlama Bölümü, Artvin, Türkiye
}

${ }^{b}$ Milli Savunma Üniversitesi, Ankara, Türkiye

İstanbul Sabahattin Zaim Üniversitesi Fen Bilimleri Enstitüsü Dergisi (2021) 3 (2): 165-170

https://doi.org/10.47769/izufbed.947977

(iD) $O R C I D{ }^{1} 0000-0002-4290-3684 ;{ }^{2} 0000-0001-6515-8667$

\begin{tabular}{|c|c|}
\hline YAYIN BİLGİSI & ÖZET \\
\hline Yayın geçmişi: & \multirow{5}{*}{$\begin{array}{l}\text { İnşaat ve dolayısıyla üretim alanı olan şantiyeler insanlık tarihi ile eş ömre sahip olup geçmişte olduğu kadar } \\
\text { günümüzde de ölümcül iş kazalarının ve geri dönülemez mühendislik-imalat-montaj hatalarının meydana } \\
\text { geldiği sahalardır. } 6331 \text { sayılı İş Sağlığı ve Güvenliği Kanunu ve gelişen teknoloji ile birlikte azaltılmış olsa } \\
\text { dahi inşaat şantiyelerinde meydana gelen iş kazaları ve hatalar hala tüm sektörler arasında üst seviyelerdedir. } \\
\text { Şantiyelerde risk gerek planlama gerekse üretim aşamalarında sürece eşlik eder. İş esnasında oluşabilecek } \\
\text { riskler, işe başlamadan önce farklı senaryolar ile değerlendirilmesi yapıldığında oluşmadan önce tedbiri } \\
\text { alınabilecektir. Bu nedenle örnek bir uygulama ile ön tehlike listesi tekniği aracılığıyla şantiye alanlarında bu } \\
\text { tip ilişkilendirme yapılmasıyla bu farklı senaryoların elde edilebilirliği ortaya konmaya çalışıldı. Ön tehlike }\end{array}$} \\
\hline Gönderilen tarih: 4 Haziran 2021 & \\
\hline Kabul tarihi: 8 Haziran 2021 & \\
\hline & \\
\hline Anahtar kelimeler: & \\
\hline Şantiye & listesi eldeki materyal ile yapılacak iş esnasında meydan gelebilecek problemlerin tahmini belirlenmesi \\
\hline Risk Değerlendirme & $\begin{array}{l}\text { işlemidir. Uygulamamızda, ETİ Krom A.Ş. Elazı̆̆ Tesislerinde Üretim A ve Üretim B kısımlarının forekazık } \\
\text { temel uygulamasında, olası gerçekleşme ihtimali olan risk değerlendirilmesi, Ön Tehlike Listesi (Primary }\end{array}$ \\
\hline PHL Tekniği & $\begin{array}{l}\text { Hazard List-PHL) tekniğine göre yapılmıştır. Risk listeleri ile sistem donanım listeleri eşleştirildi. Eşleştirme } \\
\text { sonucunda forekazık temel uygulamasında eldeki materyal ile işlem adımları sonucunda, bağıntı tehlike listesi } \\
\text { üzerinde sebep olabilecek muhtemel tehlike ilişkisi saptanmaya çalışıldı. }\end{array}$ \\
\hline
\end{tabular}

\section{Examination of Risk Assessment at Constructions With PHL Technique}

\begin{tabular}{l} 
ARTICLE INFO \\
\hline Article history: \\
Received: 4 June 2021 \\
Accepted: 8 June 2021
\end{tabular}

\section{Key words:}

Construction Site

Risk Assessment

PHL Technique

\begin{abstract}
Construction sites, which are construction and therefore production areas, have the same life as the history of humanity and are the areas where fatal work accidents and irreversible engineering-manufacturing-assembly errors occur today as well as in the past. Even though it has been reduced with the Occupational Health and Safety Law No. 6331 and developing technology, occupational accidents and errors occurring at construction sites are still at high levels among all sectors. In construction sites, risk accompanies the process in both planning and production stages. When the risks that may occur during the work are evaluated with different scenarios before starting the work, precautions can be taken before they occur. For this reason, it has been tried to reveal the feasibility of these different scenarios by making this type of association in the construction sites through an example application and the preliminary hazard list technique. The preliminary hazard list is the process of estimating the problems that may occur during the work to be done with the material at hand. In our application, ETI Krom A.Ş. In the bored pile foundation application of Production A and Production B sections in Elazig Facilities, the possible risk assessment was made according to the Primary Hazard List (PHL) technique. Risk lists and system hardware lists were matched. As a result of the matching, it was tried to determine the possible danger relationship that may cause on the correlation danger list as a result of the material at hand and the process steps in the bored pile foundation application.
\end{abstract}

*Sorumlu yazar.

E-mail adresi: selim_taskaya@artvin.edu.tr (Selim Taşkaya)

\section{Giriş}

İş yerinde fiziksel çevre koşulları, çalışılan ortamdan kaynaklı işçilerin yaşayabilecekleri mesleki sorunları ve sağlık sorunlarının minimuma düşürülmesi veya yok edilmesi amacıyla çalışmalar ve analizler ve yapılmasına iş sağlığı denilmektedir. İş sağlığı ve iş güvenliği tam manasıyla sağlaması için iş ortamlarında oluşabilecek tehlikeleri, insan ve çevre sağlığına zararlı olabilecek etmenlerin risk ve tehlike çözümlemesi yapılarak yok edilmesi gerekir (Kaygusuz, 2019). Risk analizi ve değerlendirmesi, iş yerinde veya bir maden işletmesinde yapılan gözlem neticesinde karşılaşılabilecek sorunların belirlenerek gerekli önlemlerin alınması ve gerekli çalışmalar yapılarak ortadan kaldırılması veya en aza indirgenmesi için yapılan çalışmaların tümüdür. Ülkemizde 4857 Sayılı İş Kanunu kapsamında ve AB ülkelerinde risk değerlendirmesinin yasal alt yapısını teşkil eden yeni yaklaşım direktiflerinin ana direktifi olan 89/391/EEC Direktifi doğrultusunda hazırlanarak 09.12.2003 tarih ve 25311 Sayılı Resmi Gazetede yayımlanarak yürürlüğe giren İş Sağlığı ve Güvenliği Yönetmeliği yasal alt yapıyı oluşturmaktadır (Özkılıç, 2005). Risk Analizi bir sistem içerisinde tehlikeleri belirleyerek, tehlikelerin 
oluşturabileceği riskleri tahmin eder. Riskin nelere sebep olabileceği, kabul edilebilir olup olmadığı araştırılır. Amaç riskleri ortadan kaldırmak, kaldırılamadığı durumlarda ise etkisini en aza indirebilmektir. Böylelikle daha güvenli bir çalışma ortamı sağlanmış olacak, iş kazaları önlenebilecektir (Güven, 2019). İşletmenin güvenliği için önemli olan risk analizi tehlikelerin insan üzerindeki etkisini, şiddetini, olursa sonuçlarını değerlendirmektedir. Amaç tehlikelere hızlı ve doğru cevabı verebilmek, tehditlerin ihtimalini ve olmas1 durumundaki etkisini azaltabilecek önlemleri almaktır (Aydın,2016). Ara ürünler ve bileşik ürünlerin ortaya çıtı̆̆g yer olan şantiyelerde gerek imalat aşamasında gerekse montaj aşamasında çeşitli boyutlarda riskler ortaya çıkabilmektedir. Riskler imalat sonucu ürün aşamasında olabileceği gibi üretim ara ürünleri işçi ve işyeri güvenliği açısından da olumsuz sonuçlara sebep olabilmektedir (İlter, 2015). İşleri kesintiye uğratan olayların belirlenmesi, tanımlanması, olasılığının tespiti, şiddetinin belirlenmesi, değerlendirilmesi, önlem alınması, olasılığının azaltılması, şiddetinin azaltılması ve izlenmesi risk yönetiminin aşamalarıdır. Dolayısı ile iş sürekliliği ancak başarılı bir risk yönetimi ile mümkündür. Risk analizi ise risk yönetiminin olmazsa olmaz adımıdır. Çeşitli tehlike belirleme ve risk analizi teknikleri mevcuttur (İlter, 2015).

\section{Materyal ve Yöntem}

Risk analizi; ortamdaki tehlikeleri belirleyen, onların kritik değişkenler ve fonksiyonlar üzerindeki etkilerini araştıran ve koruma amaçlı mekanizma ve stratejiler geliştiren bir süreçtir (Kahraman, 2009). Risk analizi, riskin anlaşılmasını amaçlayan yöntemler bütünüdür denilebilir (Arman, 1997: III). Risk analizi, riskin anlaşılabilirliğini geliştirmeyi sağlar. Risk değerlendirmesine ve risklerin işlenmesi gerekip gerekmediği konularında kararlar alabilmek için ve en uygun risk işleme stratejileri ve yöntemlerini belirleyebilmek için girdi sağlamaktadır (İlter, 2015).

$$
\text { Risk= Tehlike/ Önlem (İlter, 2015). }
$$

Uygulamada, Ön Tehlike Listesi (Primary Hazard List-PHL) risk değerlendirmesi seçilmiştir. Bu risk analizi yönteminin birinci amacı potansiyel sistem tehlikelerinin listelenmesi, ikinci amacı ise kritik güvenlik faktörleri ve aksilik kategorilerinin tanımlanmasıdır. Bu risk analizi yöntemi ile daha tasarım aşamasında dahi hata ve risklerin önlenmesi için adımlar atılabilir. Beyin firtınası şeklinde öne sürülen potansiyel risklerin bir listede toplanmasını sağlar. Ön tehlike listesi (ÖTL), kavramsal ve ön tasarım aşamalarında uygulanan bir tehlike analiz tekniğidir. $\mathrm{Bu}$ analizin en önemli avantajı, kısa sürede kolayca ve düşük maliyetle uygulanabilmesidir. Potansiyel tehlikelerin belirlenmesi amacıyla kullanılır. ÖTL, analiz tipleri için bir başvuru noktası ya da başlangıç noktası olarak görülebilir (İlter, 2015). Bu teknik, kavramsal tasarım ve ön tasarım aşamaları sırasında uygulanmaktadır. ÖTL detaylı ve derinlemesine değerlendirmeler için bir tehlike belirleme yöntemi değildir. Başlangıç tehlike listesini oluşturulması amaçlanır (Cho, 1998). ÖTL, bilinen ve potansiyel tehlikeleri listeler. Analist, tehlikeler konusunda sahip olduğu bilgiyi kullanarak teknik personelle görüşmesi sonucunda sistemin tasarımında bulunan tehlikeleri belirler. ÖTL sonucunda istenirse tehlikelerin nedenleri ve sınıflandırılması da yapılabilir. Bu analiz tekniğinde detaylı bilgiye ihtiyaç yoktur. İhtiyaç duyulan bilgi benzer sistemlerden ve kontrol listelerinden sağlanabilir. Analist ÖTL analizi sonucunda çıktı olarak tehlike listesini ve üst seviye aksilikler listesini elde eder (İlter, 2015).

Tasarım Bilgileri; her türlü proje, imalat bilgileri; yap1 ve imalat bilgilerinden oluşur. Ayrıca tehlike bilgileri gerek imalat ve ürün gerekse iş güvenliği açısından gereklidir. Tecrübe ve eğitim bilgileri ise her aşamada rol alan ekipman, makine, imalat ve tedbirler vb. konusunda tecrübeli ve eğitimini tamamlamış ekip için gereklidir (İş Güvenliği Kanunu, 2019). İş Sağlı̆̆ ve Güvenliği Risk Değerlendirmesi Yönetmeliğine (RDY) göre risk değerlendirmesi; tüm işyeri için tehlikeleri tanımlama, riskleri belirleme ve analiz etme, risk kontrol tedbirlerinin kararlaştırılması, dokümantasyon, yapılan çalışmaların güncellenmesi ve gerektiğinde yenileme aşamalarından oluşur (Akpınar ve Çakmakkaya, 2014). Yapılacak risk analizi; Forekazık kolonu imalatındaki risk değerlendirmesini kapsamaktadır. Risk analizi adımları;

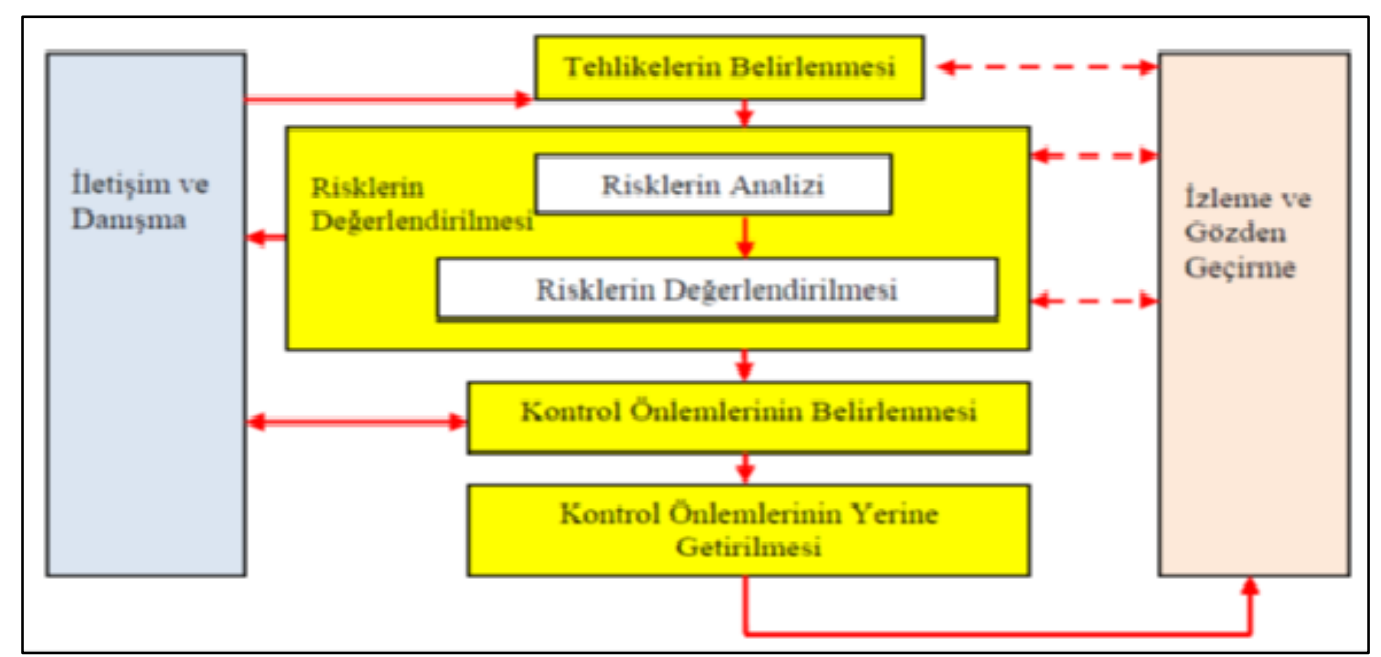

Şekil 1. Risk Yönetim Sistemine Genel Bakış (Kahraman ve Demirer, 2010).

Şekil 1.de, risk analizinin kabaca hangi işlem algoritması 1şı̆̆ında irdelemesinin basamağ 1 verilmiştir.

\section{Bulgular}

İnşaat (Yapı) sektörünün ana üretim sahası olan şantiyeler; insanlığın kullanımına yönelik her türlü yapının keşif, etüd, proje bilgileri, uygulama, imalat, montaj, kontrol vb. hizmetlerin gerçekleştirildiği inşai (yap1sal) üretim mahalleridir. İnşaat (Yap1) sektör olarak; betonarme yapılar, çelik yapılar, zemin yapıları, ulaştırma yapıları, su yapıları ve malzeme mühendisliği olmak üzere 6 (altı) ana alandan oluşmaktadır. İnşaat ve dolayısıyla üretim alanı olan şantiyeler insanlık tarihi ile eş ömre sahip olup geçmişte olduğu kadar günümüzde de ölümcül iş kazalarının ve geri dönülemez mühendislik-imalat-montaj 
hatalarının meydana geldiği sahalardır. 6331 sayılı İș Sağlığı ve Güvenliği Kanunu ve gelişen teknoloji ile birlikte azaltılmış olsa dahi inşaat mahallerinde (Şantiye) meydana gelen iş kazaları ve hatalar hala tüm sektörler arasında üst seviyelerdedir.

\section{1 Çalışma Alanı}

Uygulama alanı olarak belirlenen, ETİ Krom A.Ş. Elazı ̆̆ Tesislerinde Üretim A ve Üretim B kısımlarının Forekazık Temel çalışmasında, Ön Tehlike Listesi (Primary Hazard List-PHL) değerlendirmesi yapıldı. Forekazık, temel gömülme derinliğinin yetersiz kalacağı zemin ve kullanıma engel ölçüde hataların gerçekleşebileceği yol, köprü, gökdelen, üretim tesisi, fabrika, santral vb. yapıların dikey taşıyıcı elemanlarının yükünü temel içinde direk aktaracağı temel altı kolonları beton-betonarme yapı elemanlarına verilen isimdir.

ETI KROM A.Ş. Elazığ ili Kovancılar İlçesi Yarımca Beldesi’nde yer alan Türkiye'deki Antalya ile birlikte 2 (iki) krom işleme merkezinden biridir.

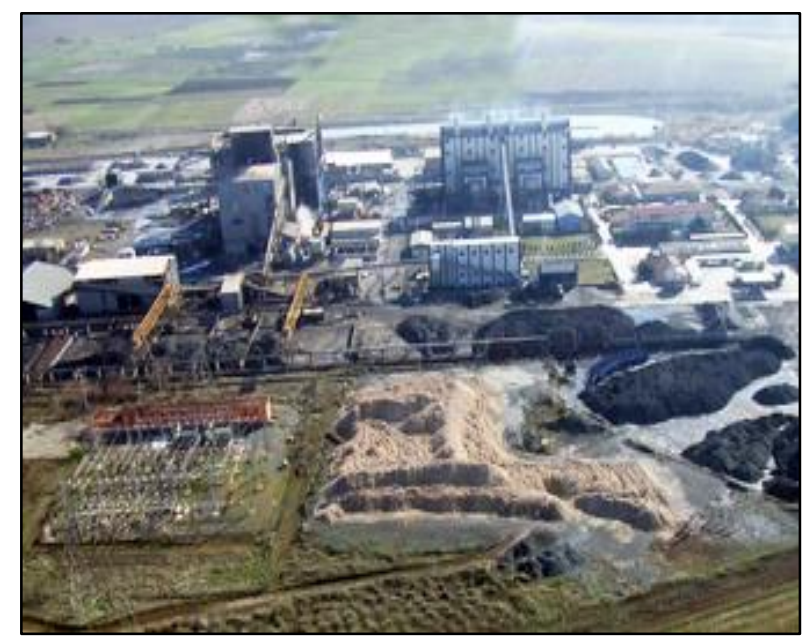

Şekil 2. Üretim alanı genel görünüş (Url3,2021).

Şekil 2. de, uygulama alanının genel görünüşü verilmiştir.

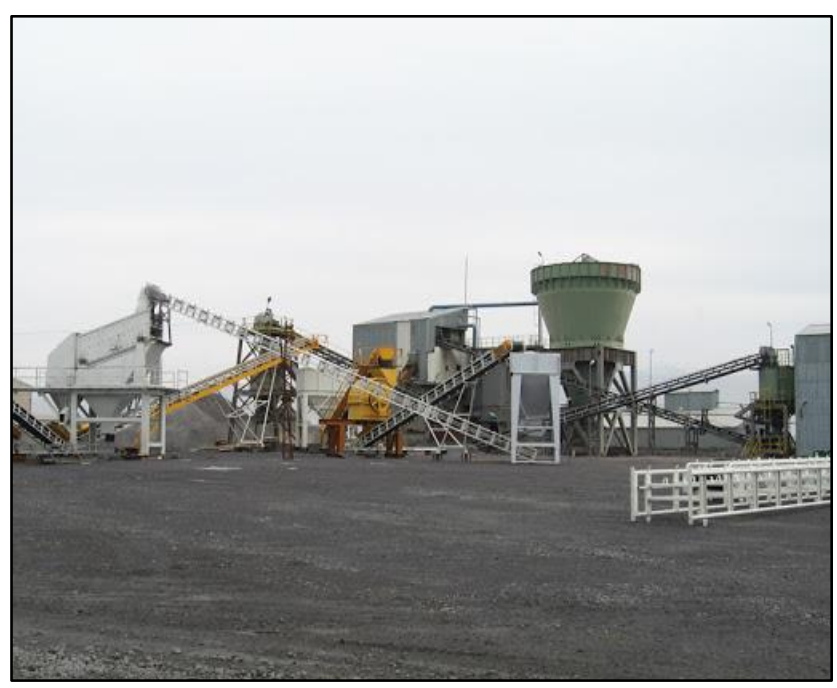

Şekil 3.Şantiye sahasının genel görünüş (Ur14, 2021). Şekil 3. de, şantiye alanından genel görünüş verilmiştir.

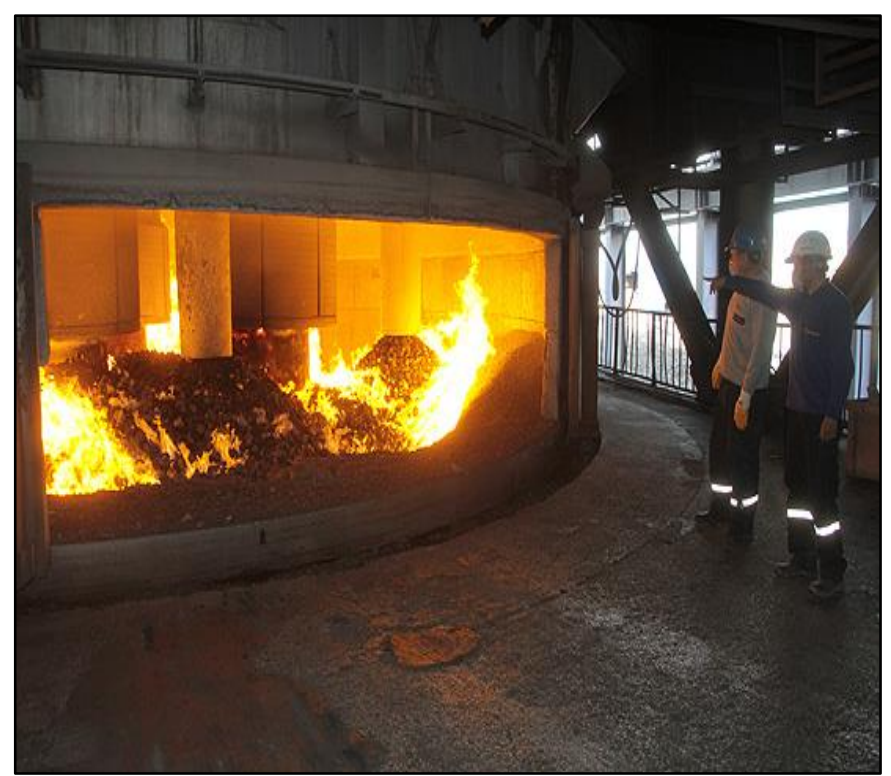

Şekil 4. Üretim alanı ocak görüntüsü (Url5, 2021).

Şekil 4. de, fabrika içerisindeki ocak firınlarından genel bir görüntü verilmiştir.

\subsection{Forekazık Sisteminin Tanımı}

Forekazık, temel gömülme derinliğinin yetersiz kalacağı zemin ve kullanıma engel ölçüde hataların gerçekleşebileceği yol, köprü, gökdelen, üretim tesisi, fabrika, santral vb. yapıların dikey taşıyıcı elemanlarının yükünü temel içinde direk aktaracağı temel altı kolonları beton-betonarme yapı elemanlarının imal edildiği yapı safhasında kullanılan sisteme verilen isimdir. Üretim tesisi temelinde, ortak çalışmak üzere üretim makinelerinin ankraj noktaları ve temelin sağlam zemin tabakasına yükünü aktarabilmesi açısından yapılan işlem çok hassas ve önemlidir (Url2, 2019). Vinç ile forekazık makinesinin temel kotuna indirilmesinden imalatın tamamlanıp makinenin ankrajına kadar önemli süreçler birbirini izler. Görev, forekazık temel bağlantısı inşa edebilmektir. Görev aşamaları; projelendirilmiş olan taşıyıcı sistemin dinamik aşamaları olan kazı, tahkimat, vinç, forekazık zemin delgisi, kolon beton dökülmesi, son 10 metresinin betonarme fretli donatısının yerleştirilmesi, kalan kısmın betonunun dökülmesi, vinç ile forekazık makinesinin temelden çıkarılması, temel ile bağlantısının kurulması ve üretim makinelerinin ankrajı şeklinde tanımlanabilir. Görev çevresi, uygulamanın yapıldığı şantiye alanı olan ETIKROM A.Ş. Üretim A ve Üretim B tesis inşaatlarıdır. Forekazık Makinesi tasarımı; İKSA İNŞ.Yapı Makineleri tarafından yapılmıştır. İşletimi, İKSA İnş.Yapı Makineleri tarafından yerinde uygulama şeklindedir. 


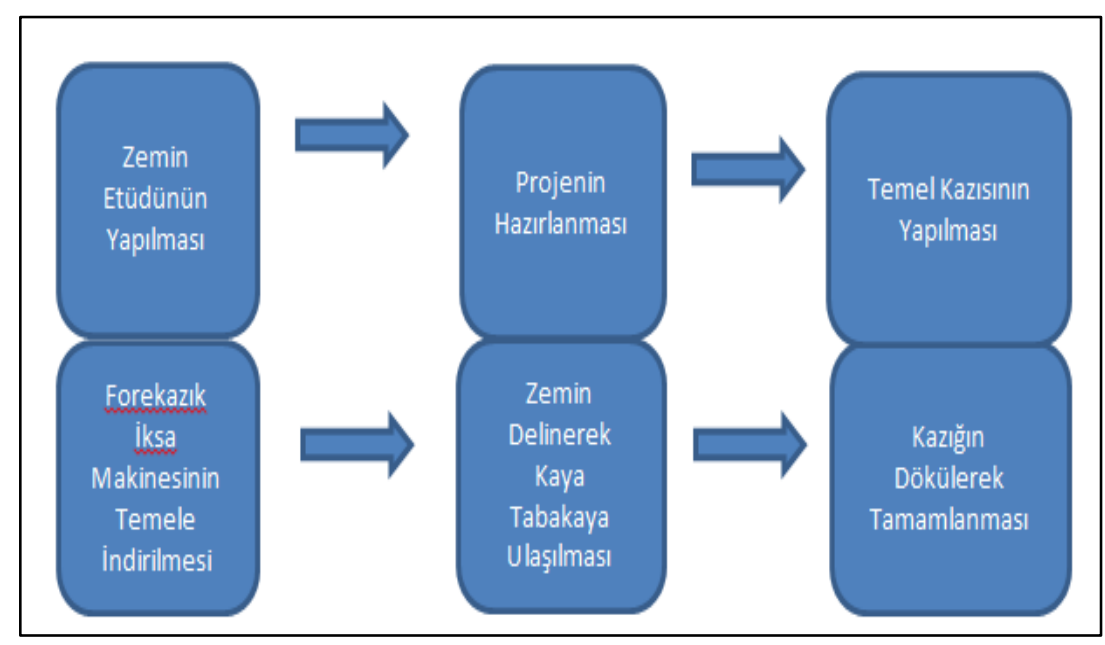

Şekil 5. Üretim Akış Şeması

Şekil 5.de, forekazık sisteminin basamak basmak iş akışı üretim şeması üzerinde neler yapılması gerekliliği gösterilmiştir.

Üretim tesisi A ve B için radyejeneral temel içine forekazık kazık kolonlar ile temel teşkili ve ankraj kolon imalatı yapılacaktır. Kalıp imalatı için her türlü dülger malzemesi (kereste, çekiç, çivi, testere, spiral vb.), betonarme forekazık demiri için her türlü demirci malzemesi (çelik tel, kerpeten, çekiç vb.), işçi güvenliği için baret, güvenli ayakkabı, fosforlu yelek, emniyet kemeri, halat, santralden gelen beton mikseri ve pompası, işyeri güvenliği için şerit, tabela, 1şıklandırma vb. forekazık makinesinin temele indirilmesi için vinç gerekli olan ekipmanlardır. Kış şartlarında ise beton dökülmesi için sika piriz hızlandırıcı, beton akışkanlaştırıcı, kalıplar için kalıp yağı vb. kimyasallar kullanılacaktır. İmalatın planlanan zaman ve hedeflenen dayanım-ergonomi ölçüsünde yapılmasıdır. Risk analizi, imalatın her aşamasında karşılaşılacak hata, kaza vb. durumların öngörülüp önlem alınmasını sağlamak için yapılır. hidrolik kısım, delgi kısmı ve beton döküm pres nozul sistemi) ile temel kazı̆̆ı (kolonu) yapılması sistemidir. Bu aşamada sistem elemanları, forekazık makinesi, vinç, beton mikseri, beton pompası, radyejeneral (tek parça tabliye) temel, kazık kolonları, temel kalıpları, topraklama, betonarme demir imalatıdır. Forekazık makinesi temel kazık kolonlarının imalinde, vinç makineyi temele indirmede, beton mikser ve pompası kolon betonu dökülmesinde, radyejeneral temel sistemi yapı projesine uygun forekazık kolonları ile birleşecek olan taşıyıcı temel tipi, temel kalıpları beton sınır elemanı, kazık kolonları temel yardımcı taşıyıcı elemanları, topraklama kullanılan elektrik enerjisi toprak bağlantısını ve betonarme demiri taşıyıcı sistem yardımcı elemanı olarak görev almaktadır. PHL'in amacı, imalat öncesi, sırası ve sonrasında meydana gelebilecek her türlü riski öngörmek ve önlem almaktır. Veriler toplama aşamasını müteakip sistem listesi ve tehlike listeleri oluşturulur, bağıntılı olanlar ilişkilendirilerek tehlike, oluşabilecek durum ve öneri ile analiz sonlandırılır.

\subsection{Forekazık Sisteminde PHL'in Planlanması}

Analizi yapılacak olan sistem Forekazık makinesi (dinamik kısım,

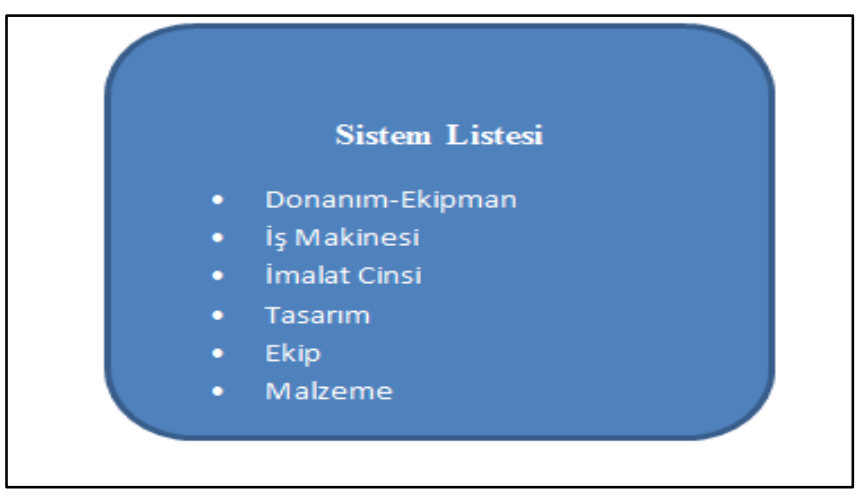

Sekil 6. Sistem Listesi

Şekil 6.da, gerekli tüm tasarım, makine-ekipman kullanım ve

yapılacak işlem verileri ekip tarafindan toplanarak incelendi. 
Taşkaya ve Can (2021) İZÜ Fen Bilimleri Enstitüsü Dergisi 3 (2)

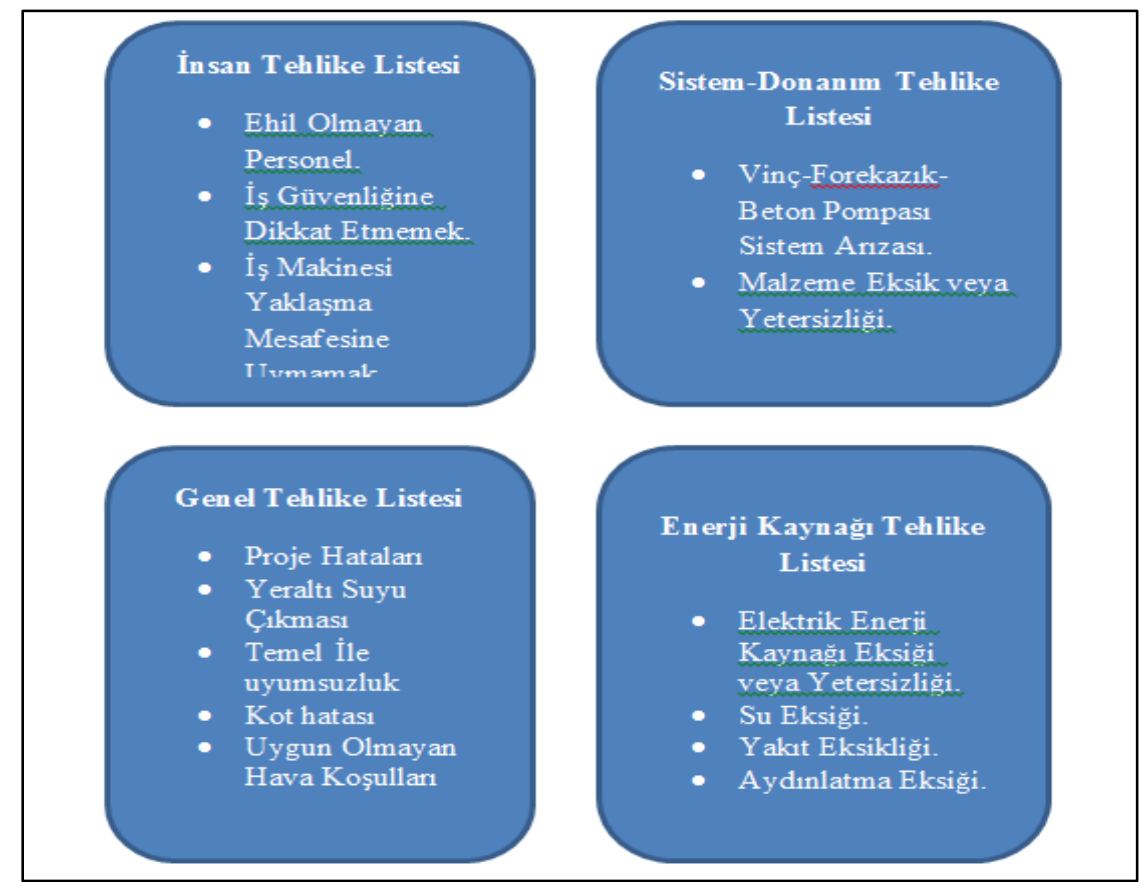

Şekil 7. Tehlike Listesi

Şekil 7.de, çeşitli şekilde risk oluşturacak tehlike listeleri verilmeye çalışıldı.

\subsection{PHL'nin Gerçekleştirilmesi}

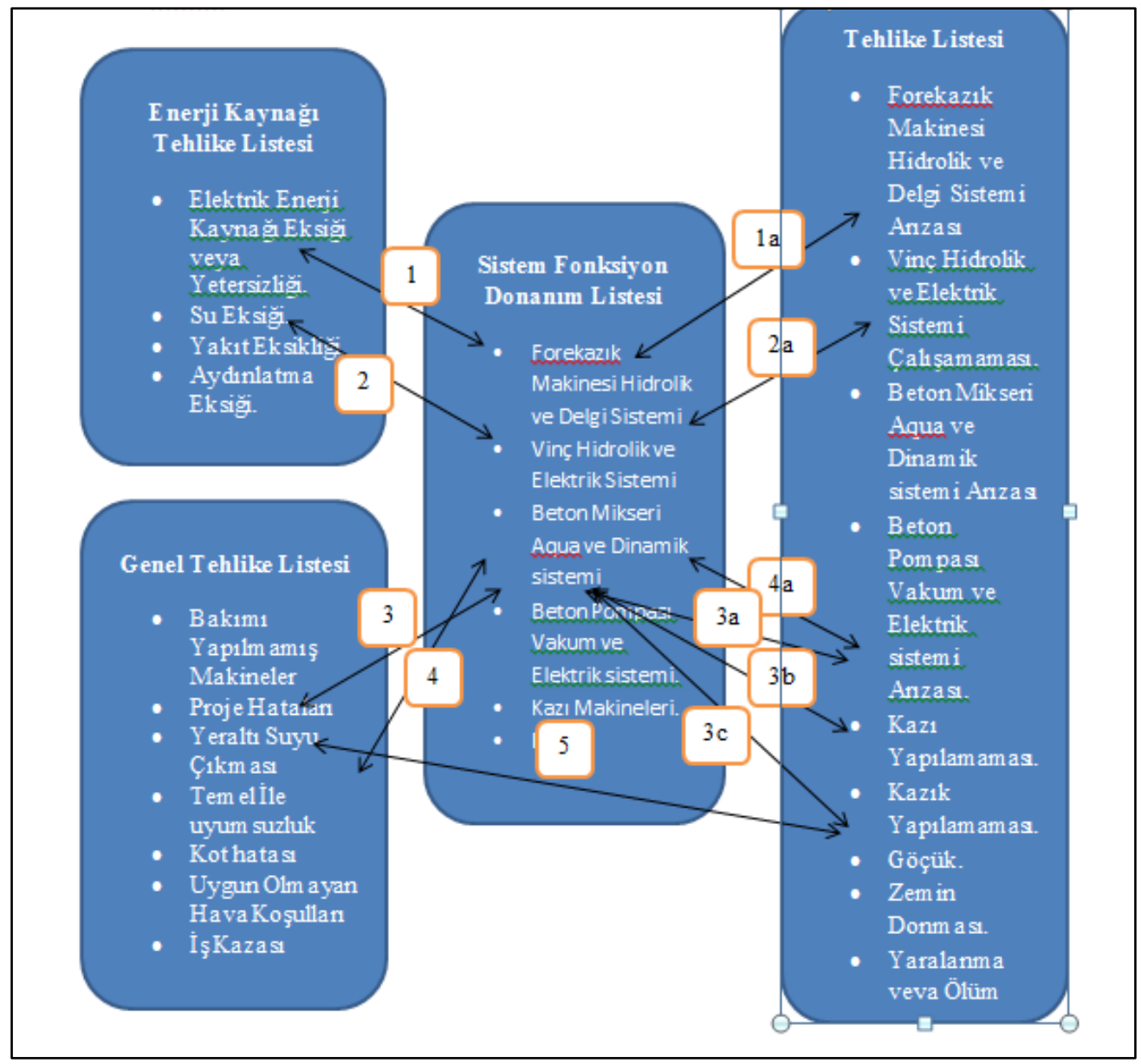

Şekil 8. PHL ile duruma göre ilişkilendirme 
Şekil 8.de, meydan gelmesi olası risklerin, iş akışı sırasındaki varyansı incelenmeye çalışıldı. Uygulamadaki sistem fonksiyonu donanım listelerinin meydana gelmesi muhtemel enerji kaynağ tehlikeler ile sonuçları arasındaki ilişki ağı kuruldu.

Çizelge 1. Ön Tehlike Listesi Analiz Formu

\begin{tabular}{|c|c|c|c|c|}
\hline \multicolumn{5}{|c|}{$\begin{array}{l}\text { Ön Tehlike Listesi Analizi } \\
\text { Sistem Elemanı: Enerii Ka }\end{array}$} \\
\hline Sira & $\begin{array}{l}\text { Sistem } \\
\text { Bileșeni }\end{array}$ & Tehlike & Tehlike Etkileri & Öneriler \\
\hline 1 & $\begin{array}{l}\text { Su eksiği ve } \\
\text { yetersizliği }\end{array}$ & $\begin{array}{l}\text { Forekazık makinesi delgi ucu su } \\
\text { nozulu yeteri basınçla } \\
\text { çalışamayacağından forekazık } \\
\text { uygulamasının yapılamayacak } \\
\text { olması. }\end{array}$ & $\begin{array}{c}\text { Forekazık uygulaması } \\
\text { yapılamadığı için temel } \\
\text { tamamlanamayacak ve proje } \\
\text { aksayacaktır. }\end{array}$ & $\begin{array}{c}\text { Şebeke suyu yetersizliği ya da } \\
\text { kesintisi ihtimaline karşı } \\
\text { tanker ile su } \\
\text { bulundurulmalıdır. }\end{array}$ \\
\hline 2 & $\begin{array}{l}\text { İmalat sahası } \\
\text { aydınlatma } \\
\text { yetersizliği }\end{array}$ & $\begin{array}{c}\text { Yeterli aydınlatma } \\
\text { sağlanamaması durumunda } \\
\text { imalatın her aşamasında güçlük } \\
\text { yaşanabilir. }\end{array}$ & $\begin{array}{c}\text { Vinç ile forekazık makinesinin } \\
\text { temele indirilmesi, beton pompa } \\
\text { ve makine aktarmalarında } \\
\text { yaşanacak sorun neticesinde } \\
\text { imalat } \\
\text { gerçekleştirilemeyecektir. }\end{array}$ & $\begin{array}{l}\text { Aydınlatma için mevcut } \\
\text { kaynaklara ek olarak dizel } \\
\text { jeneratörlü yüksek lümenli } \\
\text { yeterli sayıda projektör temin } \\
\text { edilmeli ve sahaya tespit } \\
\text { edilmelidir. }\end{array}$ \\
\hline 3 & Kot hatas1 & $\begin{array}{l}\text { Temel kotu veya kazı kotunun } \\
\text { hatalı olması durumunda } \\
\text { forekazık kolon aplikasyonu } \\
\text { uygulanamayabilir. }\end{array}$ & $\begin{array}{c}\text { Forekazık uygulaması } \\
\text { yapılamadığı için temel } \\
\text { tamamlanamayacak ve proje } \\
\text { aksayacaktır. }\end{array}$ & $\begin{array}{c}\text { Kazı kotu ve temel kotu } \\
\text { Harita Mühendisi tarafindan } \\
\text { zemine uygulama aşamasında } \\
\text { kontrol edilmelidir. }\end{array}$ \\
\hline 4 & $\begin{array}{l}\text { Uygun } \\
\text { olmayan hava } \\
\text { koşulları }\end{array}$ & $\begin{array}{l}\text { Uygun olmayan hava koşulları, } \\
\text { imalat dönemi kış mevsimine } \\
\text { rastlayacağı için imalatta } \\
\text { güçlüklere neden olacaktır. }\end{array}$ & $\begin{array}{l}\text { Zeminde don, kar yağışı ile } \\
\text { zemin yumuşaması, aşırı soğuk } \\
\text { koşullarda çalışamama vb. } \\
\text { etkiler ile temel } \\
\text { tamamlanamayacak ve proje } \\
\text { aksayacaktır. }\end{array}$ & $\begin{array}{l}\text { Havanın fen noktasından } \\
\text { çalışılmaya uygun olmayan } \\
\text { devresinde imalat } \\
\text { yapılmamalıdır. }\end{array}$ \\
\hline 5 & İş kazası & $\begin{array}{c}\text { İş makinesi, kazı, delgi, montaj, } \\
\text { yatay ve düşey taşıma } \\
\text { aşamalarında iş kazası meydana } \\
\text { gelebilir. }\end{array}$ & $\begin{array}{c}\text { İş kazası yaralanma ya da } \\
\text { ölümle sonuçlanabilir. Proje } \\
\text { tamamlanmaz, işçi } \\
\text { kaybedilebilir. }\end{array}$ & $\begin{array}{l}\text { İş Sağlığ1 ve Güvenliği } \\
\text { Kanununa uygun ekipman, } \\
\text { eğitim, kontrol vb. } \\
\text { sağlanmalıdır. }\end{array}$ \\
\hline
\end{tabular}

Çizelge 1.de, sistem bileşenleri doğrultusunda tehlike etmenlerine karşılık gelecek tehlike etkileri ile bu etkiler doğrultusunda alınabilecek tedbirlere ilişkin öneriler getirildi.

\section{Sonuç}

Risk analizinin imalat safhasından önce yapılması; zaman kayb1, malzeme kaybı, ödenek kaybı, bağlantılı işlerin gecikmesi, işgücü kaybı vb. durumların oluşmasını engelleyeceği için riski en aza indirmekte ve önlenebilir seviyeye getirmektedir. Risk analizinin yapılması projenin de sahaya doğru olarak uygulanmasını sağlayacağı için ortaya çıkan yapı da o derecede uygun hizmet verebilecektir. Araştırmanın amacı risk analizi yaparak ortadan kaldırmaktır. Araştırma sonucu riskleri azaltmak ya da ortadan kaldırmak imalat kalitesini artıracak, zaman kaybına engel olacak ve iş güvenliği konusunda avantaj sağlayacaktır. İmalat ve uygulama öncesinde belirlenen su eksiği ve yetersizliği, imalat sahası aydınlatma yetersizliği, kot hatası, uygun olmayan hava koşulları ve iş kazası muhtemel riskleri öngörülmüş, bu risklerin oluşturabileceği tehlikeler belirlenmiş, tehlikelerin etki edeceği tüm koşullar değerlendirilerek öneriler ile tehlike boyutu engellenmeye çalışılarak risk analizi tamamlandi. Uygulamada Ön tehlike listesi, ekipman doğrultusunda korelasyona tabi tutularak ilişkiler saptanmaya çalışıldı. Ön Tehlike Listesi (Primary Hazard List-PHL) yönteminin dezavantajının olmadığı görülüp, kazaların bu öngörü senaryolarıyla engellenebileceği ortaya kondu.

\section{Kaynaklar}

Akpınar,T., Çakmakkaya,Y.B., 2014.İş Sağlığı Ve Güvenliği Açısından İşverenin Risk Değerlendirme Yükümlülüğü. Çalışma Ve Toplum, 1:273-304.

Arman, T. (1997). Risk Analizine Giriş, İstanbul: Alfa Basım Yayım, III.

Aydın, F., 2016. Risk Değerlendirme Yöntemi FMEA'nın Bir Tekstil Fabrikasına :Uygulanması. Yüksek Lisans Tezi, Gazi Üniversitesi, Fen Bilimleri Enstitüsü, Ankara.

Cho, F. L. , American Society of Mechanical Engineers , (1998, July). "Risk assessment technologies, and transportation, 
storage, and disposal of radioactive materials". Paper presented at ASME/JSME Joint Pressure Vessels and Piping Conference,22-23.

GÜVEN Nurçin, TALAŞLI IMMALAT SEKTÖRÜNDE RISKK ANALİŻ, Yüksek lisans Tezi, 2019.

İLTER İ., 2015. BİLIŞIM HİZMETLERINIIN SÜREKLİLİĞİNE YÖNELIK RİSK ANALIZİ: BİR KAMU KURUMU UYGULAMA ÖRNEĞİ. Yüksek Lisans Tezi Yönetim Bilişim Sistemleri, Gazi Üniversitesi, Bilişim Enstitüsü, Ankara.

Kahraman, Ö. (2009), Bir Otomobil Fabrikasında İSG Alanında FMEA Yöntemi İle Risk Analizi, Yüksek Lisans Tezi, Sakarya Üniversitesi Fen Bilimleri Enstitüsü, Sakarya, 9.

Kahraman O., Demirer A., 2010. OHSAS 18001 Kapsamında FMEA Uygulamas1. Makine Teknolojileri Elektronik Dergisi, 7 (1) 53-68.

Kaygusuz Rıza, Beton Sektöründe İş Sağlığı ve Güvenliği, Yüksek Lisan Tezi, 2019.

Özkılıç Ö. (2005). İş Sağlığı ve Güvenliği Yönetim Sistemleri ve Risk Değerlendirme Metodolojileri. Kitap No: 246. Ankara: Türkiye İşveren Sendikaları Konfederasyonu (TISK) Yayınları.

6331 Sayılı İş Sağlığı ve Güvenliği Kanunu, 2019.

Risk Değerlendirme Yönetmeliği, 2012.

Url1:https://www.google.com/search?q=risk+de\%C4\%9Ferlendirme +y\%C3\%B6netmeli\%C4\%9Fi\&rlz=1C1FHFK_trTR937 TR937\&oq=risk+de\%C4\%9Fe\&aqs=chrome.2.69i57j016 j69i60.4403j0j7\&sourceid $=$ chrome \&ie $=$ UTF- 8

Url2:https://yfk.csb.gov.tr/yuksek-fen-kurulu-kararlari-i-81847, 2019.

Url3:https://www.google.com.tr/search?q=elaz\%C4\%B1\%C4\%9F+e ti+krom\&sxsrf=ALeKk03s2Xp0iCEccdQkJeik50Iyr9cy Hw: $1623056258587 \&$ source $=1 \mathrm{nms} \&$ tbm $=\mathrm{isch} \& \mathrm{sa}=\mathrm{X} \& \mathrm{v}$ ed=2ahUKEwixv_jdk4XxAhVIgfOHHYmnCzIQ_AUoA XoECAEQAw\&biw $=1360 \&$ bih $=625 \#$ imgrc $=$ ZYPASNc dK_hYLM

Url4:https://www.google.com.tr/search?q=elaz\%C4\%B1\%C4\%9F+e ti+krom\&sxsrf=ALeKk03s2Xp0iCEccdQkJeik50Iyr9cy Hw: $1623056258587 \&$ source $=$ lnms\&tbm $=i s c h \& s a=X \& v$ ed=2ahUKEwixv_jdk4X

xAhVIgf0HHYmnCzIQ_AUoAXoECAEQAw\&biw=1360\&bih=62 $5 \#$ \#imgrc $=6 \mathrm{AZaAhA} 4 \mathrm{TnntRM}$

Url5:https://www.google.com/search?q=eti+krom\&rlz=1C1FHFK_tr TR937TR937\&sxsrf=ALeKk02z-

iOhapFT6TJk_4WTIejLZhF-

bg: $1623061635207 \&$ source $=1$ nms \&tbm $=$ isch \&sa $=X \& v e$ $\mathrm{d}=2 \mathrm{ahUKE}$

wiDtNvhp4XxAhVfhP0HHXX8DrkQ_AUoAnoECAEQBA\&biw=1 360\&bih=625\#imgrc=LQETqZ1UsZwTYM. 